\title{
Mechanisms of thrombosis in ANCA-associated vasculitis
}

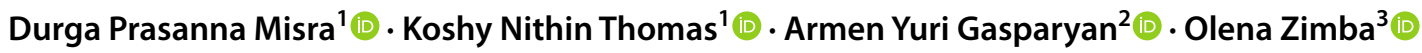

Received: 4 April 2021 / Revised: 7 May 2021 / Accepted: 22 May 2021 / Published online: 9 June 2021

(c) International League of Associations for Rheumatology (ILAR) 2021

\begin{abstract}
Patients with anti-neutrophil cytoplasmic antibody (ANCA)-associated vasculitis (AAV) have a two- to threefold greater risk of developing venous as well as arterial thrombotic events. Although such thrombotic events are more commonly seen during phases of active AAV, they are also recognized to occur during AAV in remission. Endothelial injury is a key pathogenic event in AAV. Endothelial injury can be caused by neutrophil activation and release of thrombogenic tissue factor into the circulation. Neutrophil activation further results in the formation of neutrophil extracellular traps (NETs). NETs contribute to thrombosis by expressing tissue factor. NETs have also been detected in cutaneous thrombi from patients with AAV induced by hydralazine. Activated neutrophils in AAV patients release thrombogenic microparticles loaded with tissue factor which further enhances clotting of blood. Antiphospholipid antibodies (APLs) have been detected in up to a third of AAV and might also be induced by drugs such as cocaine adulterated with levamisole and propylthiouracil, which are known to trigger AAV. Such APLs further drive the thrombosis in AAV. Once thrombogenesis occurs, the homeostatic mechanisms resulting in clot dissolution are further impaired in AAV due to antiplasminogen antibodies. The ongoing pandemic of coronavirus disease 2019 (COVID-19) is associated with endothelial injury and NETosis, mechanisms which are in common with AAV. Reports of new-onset AAV following COVID-19 have been described in the literature, and there could be shared mechanisms driving these processes that require further evaluation.
\end{abstract}

Keywords Anti-neutrophil cytoplasmic antibody-associated vasculitis · Antiphospholipid antibodies · Deep vein thrombosis $\cdot$ Embolism and thrombosis $\cdot$ Neutrophil extracellular traps $\cdot$ Vascular endothelium

\section{The association of anti-neutrophil cytoplas- mic antibody (ANCA) and ANCA-associated vasculitis with thrombosis}

Anti-neutrophil cytoplasmic antibody (ANCA)-associated vasculitis (AAV) refers to a group of systemic diseases pathogenetically linked by small vessel vasculitis, presenting with myriad clinical features involving the lungs, kidneys, peripheral nerves, and other internal organs [1]. When AAV was first recognized, they were associated with early

Durga Prasanna Misra

durgapmisra@gmail.com

1 Department of Clinical Immunology and Rheumatology, Sanjay Gandhi Postgraduate Institute of Medical Sciences (SGPGIMS), Lucknow, India

2 Departments of Rheumatology and Research and Development, Dudley Group NHS Foundation Trust (Teaching Trust of the University of Birmingham, UK), Russells Hall Hospital, Dudley, West Midlands, UK

3 Department of Internal Medicine \#2, Danylo Halytsky Lviv National Medical University, Lviv, Ukraine mortality in nearly $90 \%$ patients [2]. Over the past three decades, the recognition of cyclophosphamide and rituximab as potent therapies for remission induction in AAV has markedly improved the outlook, with long-term survival in nearly $90 \%$ patients $[2,3]$. Longer survival in patients with AAV has brought into focus the impact of comorbid conditions on these individuals $[4,5]$. Increasing attention has focused on the higher risk of venous and arterial thromboses in AAV.

The risk of venous thrombotic events [deep venous thrombosis (DVT), pulmonary thromboembolism (PTE)] as well as arterial thrombotic events (ATE) leading on to cardiovascular disease (CVD) or coronary artery disease (CAD) is increased in patients with AAV, summarized in Table 1 [6-11]. These findings have been observed across population-based observational cohorts as well as in patients recruited for participation in clinical trials of AAV. Some studies have reported a greater risk of thrombotic events in those with renal involvement due to AAV [8,9]. This risk might be driven in part by the loss of anti-thrombotic factors in urine of patients with renal involvement, although this is more common with nephrotic syndrome rather than with the glomerulonephritis usually seen in AAV [12]. While most 
Table 1 Risk of thrombotic events in patients with ANCA vasculitis

\begin{tabular}{|c|c|c|c|}
\hline Reference number, location & Type of study & $\mathrm{n}$ & Key findings \\
\hline [6] Germany & Retrospective cohort & 105 & - 13 VTE episodes (2 fatal due to PTE) \\
\hline [7] North America & Population-based cohort & 58 & $\begin{array}{l}\text { - Over 6.5-year median follow-up, HR (95\% CI) for CVD adjusted } \\
\text { for age, gender, and time of recruitment to the cohort was } 3.15 \\
\text { (1.51-6.57). HR increased when traditional CVD risk factors were } \\
\text { adjusted for (HR 4.62, 95\% CI 1.87-11.42) } \\
\text { - HR for VTE was } 3.26 \text { [6.25 for DVT and } 1.33 \text { for PTE; increased } \\
\text { HR for VTE and PTE not statistically significant]. Highest risk for } \\
\text { CVD in the first } 2 \text { years following diagnosis }\end{array}$ \\
\hline [8] USA, Netherlands & Clinical trial of rituximab in AAV & 197 & $\begin{array}{l}\text { - VTE in } 8.1 \% \text { individuals. Occurred early [median } 1.5 \text { (range 1-2.75) } \\
\text { months following enrollment] } \\
\text { - Factors associated with VTE risk on multivariable-adjusted analy- } \\
\text { ses: } \\
\text { - Cardiac involvement (HR 21.84, 95\% CI } 2.56-185.81 \text { ) } \\
\text { - Pulmonary hemorrhage (HR 3.91, 95\% CI 1.45-10.52) } \\
\text { - Urinary red cell casts (HR } 16.46,95 \% \text { CI 3.61-75.08) } \\
\text { - Anti-PR3 antibody positive AAV (HR 9.12, 95\% CI 1.16-71.84) }\end{array}$ \\
\hline [9] Europe & Clinical trials of AAV by the EUVAS & 417 & $\begin{array}{l}\text {-VTE in } 9.8 \% \\
\text { - Factors associated with VTE risk on multivariable-adjusted analy- } \\
\text { ses: } \\
\text { - Increasing CRP levels } \\
\text { - Cutaneous or gastrointestinal involvement } \\
\text { - Impaired renal function at baseline }\end{array}$ \\
\hline [10] UK & Retrospective cohort & 204 & $\begin{array}{l}\text { - Follow-up } 1088 \text { person-years } \\
\text { - Incidence of ATE of } 2.67 \text { [CAD 1.56, stroke 1.1] per } 100 \text { person- } \\
\text { years and VTE of } 1.47 \text { [DVT 0.83, PTE } 0.64 \text { ] per } 100 \text { person-years } \\
\text { - AAV had } 15 \text { times higher risk of CAD, } 11 \text { times greater risk of } \\
\text { stroke and } 20 \text { times greater risk of VTE versus the general popula- } \\
\text { tion } \\
\text { - The risk of vascular thrombotic events was highest in the first year } \\
\text { following diagnosis } \\
\text { - ATE (but not VTE) associated with more risk of mortality }\end{array}$ \\
\hline [11] Russia & Retrospective cohort & 357 & $\begin{array}{l}\text { - VTE in } 8.4 \% \text { patients } \\
\text { - Most occurred in the first year following diagnosis }\end{array}$ \\
\hline
\end{tabular}

95\% CI, 95\% confidence intervals; AAV, ANCA-associated vasculitis; ANCA, anti-neutrophil cytoplasmic antibody; ATE, arterial thrombotic events; CAD, coronary artery disease; CRP, C-reactive protein; CVD, Cardiovascular disease; DVT, deep venous thrombosis; EUVAS, European Vasculitis Society; HR, hazard ratio; PR3, proteinase 3; PTE, pulmonary thromboembolism; VTE, venous thrombotic events

studies report an increased risk of venous thromboembolism (VTE) during active disease and early on during the course of AAV, studies have reported increased thrombogenic potential in peripheral blood of AAV in remission also [13].

A systematic review of observational studies confirmed the increased risk of CVD events [risk ratio (RR) of 1.65, 95\% CI 1.23-2.22] in AAV [14]. Another systemic review reported an incidence of VTE in $12.4 \%$ (95\% CI 8.8-17.2) AAV patients at a mean follow-up of 5.2 years, pooled across 21 studies. Of these VTE, $63.4 \%$ were DVT and 26.3\% PTE. Repeated episodes of VTE were reported in $10 \%$ patients. On meta-regression, greater risk of VTE was seen with anti-myeloperoxidase (anti-MPO) ANCA but not anti-PR3 ANCA. Increased baseline disease activity measured by the Birmingham Vasculitis Activity Score (BVAS) and renal involvement portended greater risk of VTE. A longer duration of follow-up also associated with increased VTE [15].
Venous thromboses might be presenting features of AAV $[16,17]$. The presence of ANCA also increases the risk of thrombosis in other vasculitides such as Behcet's disease and thromboangiitis obliterans $[18,19]$. Understanding the pathogenic factors driving the heightened risk of arterial and venous thromboses in AAV may help identify newer therapeutic approaches to ameliorate such risk. In this article, we overview the mechanisms underlying thrombosis in AAV.

\section{Search strategy}

The literature search was conducted in line with recommendations for comprehensive and systematic bibliographic searches for narrative reviews [20]. The Scopus database and MEDLINE/PubMed were searched through using the terms "thrombosis" and "ANCA vasculitis" on March 3, 2021. We retrieved 246 documents. These references were 
manually searched to identify relevant original articles and case reports discussing the epidemiological and pathophysiological aspects of thrombosis in AAV. Reference lists of notable review articles were also screened to identify additional relevant articles. Forty-one such articles were retrieved and reviewed in context. Cross-references to these articles were searched for clarification wherever the same was required. Additional articles were also selected based in the prior knowledge of the authors. The information was synthesized under the headings described below.

\section{Neutrophil extracellular traps associate with both disease activity and thrombosis in AAV}

Neutrophil activation has been recognized as a key pathogenic feature of AAV [21]. Neutrophils in AAV, particularly when they are primed by inflammatory cytokines like tumor necrosis factor alpha (TNF), increasingly express proteinase-3 (PR-3) and myeloperoxidase (MPO) granules on their surface. These granules are recognized by anti-PR3 or anti-MPO antibodies and result in neutrophil degranulation [21]. In the past decade, the generation of neutrophil extracellular traps (NETs) following de-condensation of chromatin has been recognized as a key pathological feature in renal biopsies from patients with glomerulonephritis associated with AAV [22]. These NETs serve as a persistent source of autoantigens, i.e., proteinase- 3 and myeloperoxidase, enabling their presentation to myeloid dendritic cells [23, 24]. Increased NETosis has been identified in patients with active AAV compared to inactive AAV [25]. NETosis has been identified as a pathological feature in drug-induced AAV triggered by exposure to cocaine [26] and hydralazine [27]. NETs have been identified in post-mortem venous thrombi of patients with AAV. Histone citrullination is a key step driving the generation of NETs by causing unfolding of chromatin. NETs were more abundant in post-mortem examination of venous thrombi derived from AAV as opposed to those from patients with sepsis or other causes of pulmonary thromboembolism, and these NETS also demonstrated increased histone citrullination [28]. Thus, NETs might play a role in the thrombosis associated with AAV [29].

\section{Endothelial cell injury and triggering of coagulation cascade in AAV}

The endothelial lining is critical towards homeostasis that prevents circulating blood from clotting. The intact endothelial lining separates circulating blood from tissue factor (TF) [30]. The damaged endothelium releases von
Willebrand factor (VWF), which in turn initiates platelet activation and thrombosis [31]. Exposure to tissue factor further initiates activation of clotting cascade via factor VIIa. In inflammatory states, circulating tissue factor may be further expressed on monocytes, platelets, and possibly neutrophils and eosinophils in disease states. The cellular sources of TF also release this into the circulation in the form of microparticles containing tissue factor [30]. The measurement of tissue factor pathway inhibitor, which is an anticoagulant response of the body following the activation of tissue factor, might indicate activation of tissue factor pathway (and thereby thrombosis) [32]. The activation of circulating factors like factor VIII further drives the coagulation cascade [33]. The cleavage of prothrombin to thrombin by factor $\mathrm{Xa}$ is a critical step driving the conversion of fibrinogen of fibrin, which forms the bulk of the clot. The prothrombin fragments generated during this step therefore indicate cleavage of prothrombin to thrombin. Higher levels of plasma fibrinogen denote greater thrombogenic potential [34]. The endogenous thrombin generation potential of plasma indicates potential for thrombogenesis [35]. Clot formation is normally followed by fibrinolysis, driven by conversion of plasminogen to plasmin by the enzyme tissue plasminogen activator (tPA) in the presence of fibrin [36]. Fibrinolysis is indicated by circulating levels of D-dimer [37].

Anti-endothelial cell antibodies (AECA) have been identified in various disease states, including in AAV. Circulating AECA were detectable in 10/11 patients with propylthiouracil-induced AAV during active disease but in only 3/10 patients from the same cohort during remission. Interestingly, such AECA were not detectable in individuals with propylthiouracil-induced ANCA without clinical features of vasculitis or in healthy controls, suggesting that they might have a role in driving AAV in this situation [38]. In another study involving 6 patients with GPA who were positive for anti-PR3 ANCA, AECA were not detected. However, anti-PR3 ANCA from the serum of such individuals was able to bind in vitro to human umbilical vein endothelial cells (HUVEC). Such binding was noted despite the lack of expression of proteinase-3 on HUVEC, suggesting interaction of the anti-proteinase 3 antibodies with other antigenic targets in the HUVEC. When endothelial cells were lysed from the HUVEC culture and treated with anti-proteinase 3 antibodies, no such binding was observed. This denoted that the antigens on the endothelial cells which were bound to by anti-proteinase 3 antibodies were only expressed during the native conformation of endothelial cells [39]. Thus, the binding of ANCA to endothelial cells has the potential to cause endothelial injury, which might activate the coagulation cascade. In another experiment, in vitro exposure of HUVEC to neutrophils primed by anti-proteinase 3 antibodies and TNF induced endothelial injury and cell death, which 
was ameliorated by inhibition of myeloperoxidase [40]. These studies indicate the potential for endothelial injury in patients with AAV, both due to ANCA and other circulating antibodies such as AECA, which might be the first step triggering thrombogenesis in these individuals.

The activation of coagulation cascade is detectable in patients with AAV even without clinically apparent thrombotic events. A study compared 21 patients with renal AAV with 20 control subjects with mild renal injury and another 20 with more severe renal injury without AAV. The levels of prothrombin fragments in plasma as well as D-dimer were higher in patients with active AAV than those in remission. These parameters negatively correlated with the estimated glomerular filtration rate. Furthermore, in both active AAV and AAV in remission, the levels of factor VIII activity, VWF antigen, as well as VWF activity were elevated. When compared with disease controls, plasma prothrombin fragments, D-dimer, fibrinogen, VWF antigen, and VWF activity were elevated in AAV compared to those controls with either mild or severe renal disease. Factor VIII activity was elevated in individuals with AAV compared to those with mild renal disease only [41].

Patients with AAV in remission also have increased thrombotic risk. Increased endogenous thrombin generation potential in platelet poor plasma was noted in 27 patients with AAV in remission when compared with 36 healthy controls. In the same cohort, elevated factor VIII activity and increased levels of tissue factor pathway inhibitor were noted in AAV in remission than in healthy controls, suggesting pro-thrombotic potential in AAV in remission also. On follow-up, four individuals from this cohort developed VTE, despite persistent remission during VTE in 3/4 individuals [13].

Aberrant tissue factor activation is one of the mechanisms driving thrombosis in AAV. Neutrophils from patients with AAV have been found to express tissue factor as well as release microparticles containing tissue factor. Furthermore, the NETs generated from such neutrophils have been found to contain tissue factor. Increased circulating levels of tissue factor-containing neutrophil microparticles and higher levels of circulating deoxyribonucleic acid (DNA, which indicates ongoing aberrant NETosis, have been found in active but not in those with inactive AAV. When neutrophils isolated from healthy individuals are treated in vitro with either serum from AAV patients of immunoglobulin $\mathrm{G}$ fraction derived from such serum, they are activated to form NETs which express tissue factor, as well as release tissue factor-containing microparticles. Such microparticles resulted in elevated levels of thrombin-antithrombin complex in serum, indicating the activation of the coagulation cascade [42]. In another study, the tissue factor activity in circulating microparticles in 12 patients with AAV with VTE was elevated when compared with 29 patients with
AAV without VTE and 70 healthy controls. However, the levels of microparticles containing tissue factor did not differ between AAV patients with active disease or remission. Tissue factor expression on leukocytes is associated with significantly increased hazard of VTE both in patients with active AAV as well as in remission. This study had serial samples of AAV patients enrolled in the cohort, and the investigators were able to identify increased levels of tissue factor-containing microparticles in plasma in the months preceding VTE [43]. Thus, tissue factor-expressing microparticles derived from neutrophils appear to influence VTE risk in active $\mathrm{AAV}$ as well as $\mathrm{AAV}$ in remission.

\section{Defective fibrinolytic activity might aid clot persistence in AAV}

The fibrinolytic activity is also defective in patients with AAV. Anti-plasminogen antibodies have also been detected in AAV and associate with increased risk of VTE in AAV patients in remission [43]. While anti-proteinase 3 antibody is well recognized in AAV, another antibody commonly found in such individuals recognizes the protein derived from the complementary strand of the ribonucleic acid encoding proteinase 3 (anti-cPR3 antibody). This antibody binds with plasminogen and, in vitro, delays the process of fibrinolysis, resulting in persistence of the clot [44]. A study identified elevated levels of anti-plasminogen antibodies in patients with anti-PR3 (but not anti-MPO AAV) when compared with healthy individuals or those with DVT without AAV. In this particular study, five out of nine patients who developed future VTE had anti-plasminogen antibodies along with anti-PR3 antibodies [44].

\section{Antiphospholipid antibodies associate with thrombotic risk in AAV}

Antiphospholipid antibodies (APL) include anticardiolipin antibodies (ACLA), antibodies to beta-2 glycoprotein 1, and lupus anticoagulant (LAC). Individuals with APLs or with antiphospholipid antibody syndrome have a greater risk of thrombotic events. The prevalence of antiphospholipid antibodies in AAV is variable. In a large North American cohort of patients with multiple autoimmune diseases, ACLA were detectable in $3.8 \%$ patients with AAV [45]. In another cohort of $116 \mathrm{AAV}$ patients from the UK, persistent LAC or ACLA or a diagnosis of concomitant antiphospholipid antibody syndrome was noted in nearly a third of patients. Such patients accrued greater vascular damage in the longer term when compared to other patients in the cohort [46]. Another Korean cohort of 138 AAV patients reported APLs in 13\% patients. Patients with persistently detectable APLs in the 
context of AAV had 2.9 times greater hazard of developing venous thrombotic events than those without [47]. APLs have also been identified in patients with AAV or ANCA triggered by cocaine/levamisole [48] or propylthiouracil [49]. Thus, APLs might be a contributory factor towards thrombosis in AAV. Increasingly, NETosis is being recognized to play a role in the pathogenesis of antiphospholipid antibody syndrome [50,51], and this might form a common link between APLs and AAV.

\section{Hypertrophic pachymeningitis, AAV, and cortical venous sinus thrombosis}

A rare manifestation of AAV is hypertrophic pachymeningitis. This disorder might be associated with the development of cortical venous sinus thromboses. The mechanism driving such thrombosis is unclear. It has been proposed that vascular inflammation in the region adjoining the area of hypertrophic pachymeningitis might drive such thrombosis [52-54].

\section{Thrombosis in drug-induced AAV}

Various drugs are known to induce circulating ANCA as well as AAV [55]. Cocaine adulterated with levamisole (cocaine/levamisole)-induced vasculitis is characterized by retiform purpura and cutaneous necrotic lesions with demonstrable vascular thrombi in skin biopsies [56-58]. Lupus anticoagulant positivity has been identified in nearly one-half patients, and IgM ACLA have been identified in about two-thirds of patients with cocaine-/ levamisole-induced AAV. The presence of APLs might be one of the mechanisms driving vascular thrombosis in this setting [48]. Propylthiouracil is another drug associated with AAV. Cutaneous necrosis accompanied by vascular thromboses, cerebral infarcts, as well as DVT has been reported in such patients. ACLA and LAC have also been detected in such individuals [59, 60]. Hydralazine is another cause of drug-induced AAV. Cutaneous vascular thromboses have been identified in hydralazine-induced AAV. Demonstrable NETs in such thrombi possibly indicate a role for NETosis in driving vascular thromboses in this setting [27].

\section{Infections triggering thrombosis and endothelial activation and AAV}

Patients with AAV on immunosuppressive therapy have a greater predisposition to develop opportunistic infections such as with cytomegalovirus. Cytomegalovirus infection directly causes endotheliitis by replicating in the endothelial cells, which might trigger vascular thrombosis resulting in DVT and PTE [61]. Infective endocarditis is another trigger of endothelial injury which might be associated with detectable anti-neutrophilic cytoplasmic antibodies, particularly to proteinase-3 [62, 63]. Such presentations might mimic AAV and, however, need to be carefully distinguished to avoid immunosuppressive therapy which might result in flare-up of bacterial endocarditis.
Fig. 1 Immunothrombosis in COVID-19 and ANCAassociated vasculitis: shared mechanisms

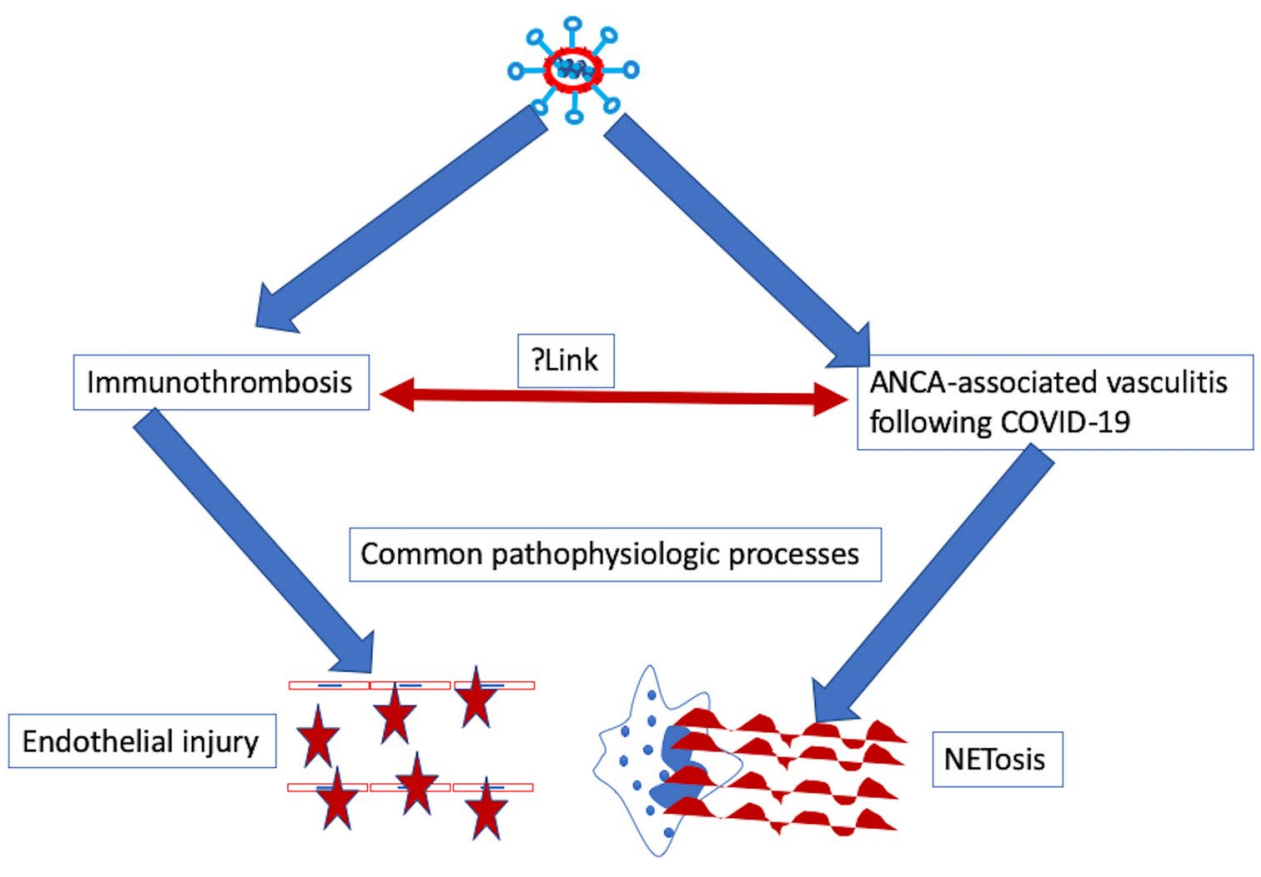




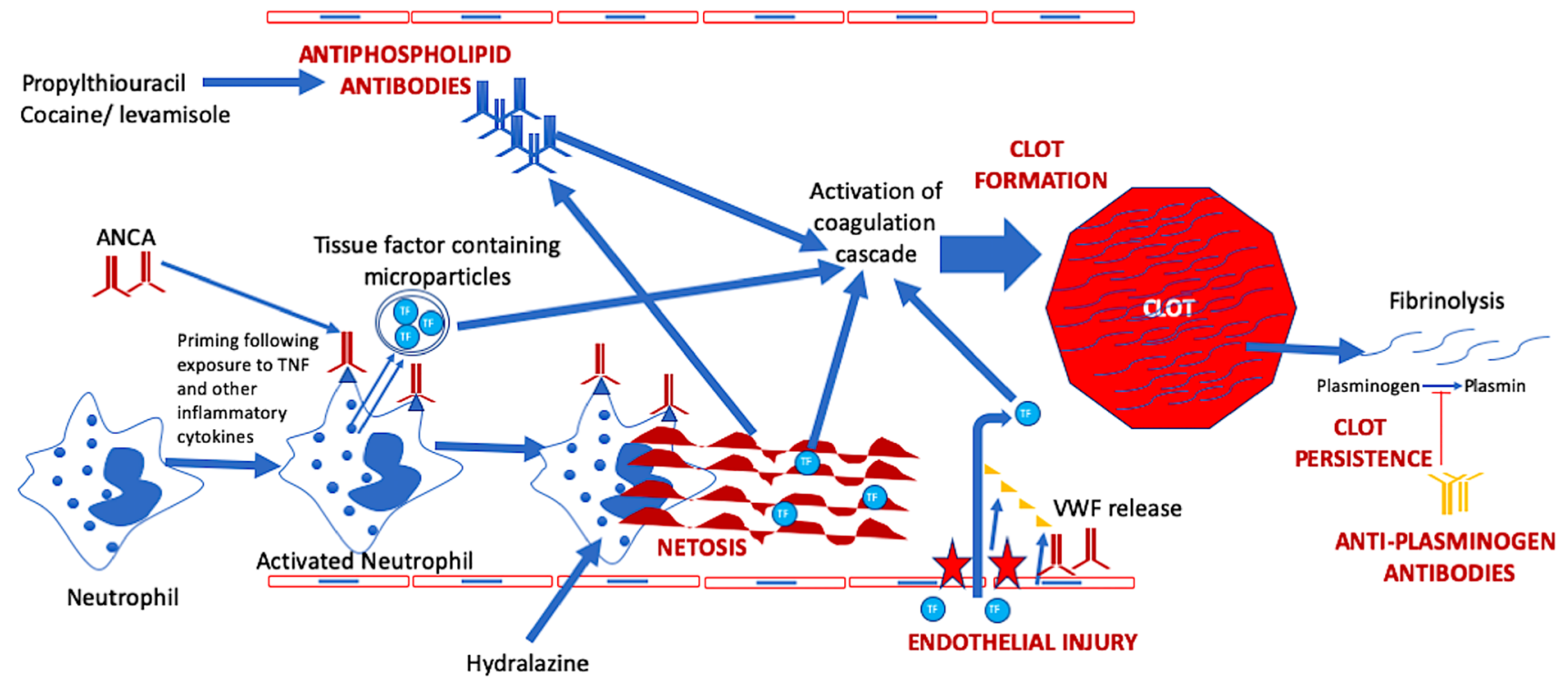

Fig. 2 Mechanisms driving thrombosis in ANCA-associated vasculitis. ANCA, anti-neutrophil cytoplasmic antibody; TF, tissue factor; VWF, von Willebrand factor

\section{Immunothrombosis in the context of COVID-19 and AAV: is there a relationship?}

In the context of the ongoing coronavirus disease 19 (COVID-19) pandemic, thrombotic manifestations occurring as a consequence of endotheliitis have been well recognized [64]. One of the mechanisms driving such thrombosis in COVID-19 is the activation of neutrophils resulting in the formation of NETs $[65,66]$. Case reports of AAV occurring after diagnosis of COVID-19 have also been reported in the literature [67-72]. Although demonstrable vascular thromboses could not be identified in any of these reports, it is known that vascular thromboses might follow diagnosis of AAV. Therefore, it is possible that the mechanisms driving immunothrombosis might be similar to those driving the induction of AAV in these individuals (Fig. 1).

\section{Conclusion}

Increased risk of venous as well as arterial thrombosis has been seen in patients with AAV, both during active disease as well as during periods of quiescence. The circulatory milieu in patients with AAV is pro-thrombotic. Endothelial injury, a key pathogenic feature of AAV, also aids thrombogenesis. The presence of antiphospholipid antibodies further contributes towards thrombotic risk in a subset of AAV, particularly in secondary AAV following exposure to cocaine/levamisole. The presence of antiplasminogen antibodies further retards the dissolution of formed clots in AAV, thereby perpetuating the persistence of clot. Platelets are known to play a role in thrombogenesis and elevated platelet counts as well as increased platelet-lymphocyte ratio associate with disease activity in AAV [73, 74]. However, there is little direct evidence to link platelets with increased thrombotic risk in AAV. Figure 2 summarizes the mechanisms driving thrombosis in the setting of AAV. Understanding the mechanisms of thrombogenesis in AAV might aid clinical management of these patients. However, clinical guidance for managing thrombosis in AAV is sparse. The authors opine that in active AAV, disease activity should be controlled with immunosuppressive agents, with anticoagulation administered until clot dissolution has been documented. In quiescent AAV, pro-thrombotic milieu is more likely to be the cause of any untriggered thrombotic event, in which case a search for APLs should be conducted. Such patients might possibly require a longer duration of anticoagulation. Data to guide the role of antiplatelet agents in this setting is sparse.

Abbreviations $A A V$, ANCA-associated vasculitis; $A C L A$, Anticardiolipin antibodies; $A E C A$, Anti-endothelial cell antibodies; ANCA, Anti-neutrophil cytoplasmic antibody; $A P L s$, Antiphospholipid antibodies; $A T E$, Arterial thrombotic events; $c P R 3$, Complementary Proteinase-3; $C A D$, Coronary artery disease; $C R P$, C-reactive protein; COVID-19, Coronavirus disease 2019; CVD, Cardiovascular disease; $D V T$, Deep venous thrombosis; $E U V A S$, European Vasculitis Society; GPA, Granulomatosis with polyangiitis; $H R$, Hazard ratio; HUVEC, Human umbilical vein endothelial cells; $L A C$, Lupus anticoagulant; MPA, Microscopic polyangiitis; $M P O$, Myeloperoxidase; NETs, Neutrophil extracellular traps; PE, Pulmonary embolism; PTE, Pulmonary thromboembolism; $P R 3$, Proteinase-3; RAVE, Rituximab 
in AAV; RR, Risk ratio; $T F$, Tissue factor; $T N F$, Tumor necrosis factor alpha; $t P A$, Tissue plasminogen activator; $V W F$, Von Willebrand factor; VTE, Venous thromboembolism

\section{Author contributions}

- Conception and design of the study - DPM and AYG; acquisition and analysis and interpretation of data - DPM, KNT, OZ, and AYG.

- Drafting the article - DPM and KNT; revising the article critically for important intellectual content $-\mathrm{OZ}$ and $\mathrm{AYG}$

- Final approval of the version to be submitted - DPM, KNT, $\mathrm{AYG}$ and $\mathrm{OZ}$

- Agreement to be accountable for all aspects of the work in ensuring that questions related to the accuracy or integrity of any part of the work are appropriately investigated and resolved - DPM, KNT, $\mathrm{AYG}$, and $\mathrm{OZ}$

Funding SGPGIMS Intramural Research Grant (Ref. No. PGI/DIR/ RC/656/2020) to Durga Prasanna Misra for research on ANCA-associated vasculitis.

\section{Declarations}

Disclosures None.

Disclaimer All the figures used in the paper are original and not copied from elsewhere.

\section{References}

1. Jennette JC, Falk RJ, Bacon PA et al (2013) 2012 revised International Chapel Hill Consensus Conference Nomenclature of Vasculitides. Arthritis Rheum 65:1-11. https://doi.org/10.1002/ art. 37715

2. Misra DP, Naidu G, Agarwal V, Sharma A (2019) Vasculitis research: current trends and future perspectives. Int J Rheum Dis 22(Suppl 1):10-20. https://doi.org/10.1111/1756-185x.13370

3. Misra DP, Naidu GSRSNK, Sharma A (2019) Recent advances in the management of antineutrophil cytoplasmic antibody-associated vasculitis. Indian J Rheumatol 14:218-228. https://doi.org/ 10.4103/injr.injr_141_19

4. Ahmed S, Gasparyan AY, Zimba O (2021) Comorbidities in rheumatic diseases need special consideration during the COVID-19 pandemic. Rheumatol Int 41:243-256. https://doi.org/10.1007/ s00296-020-04764-5

5. Misra DP, Shenoy SN (2017) Cardiac involvement in primary systemic vasculitis and potential drug therapies to reduce cardiovascular risk. Rheumatol Int 37:151-167. https://doi.org/10.1007/ s00296-016-3435-1

6. Weidner S, Hafezi-Rachti S, Rupprecht HD (2006) Thromboembolic events as a complication of antineutrophil cytoplasmic antibody-associated vasculitis. Arthritis Care Res (Hoboken) 55:146-149. https://doi.org/10.1002/art.21704

7. Berti A, Matteson EL, Crowson CS, Specks U, Cornec D (2018) Risk of cardiovascular disease and venous thromboembolism among patients with incident ANCA-associated vasculitis: a 20-year population-based cohort study. Mayo Clin Proc 93:597-606

8. Kronbichler A, Leierer J, Shin JI et al (2019) Association of pulmonary hemorrhage, positive proteinase 3 , and urinary red blood cell casts with venous thromboembolism in antineutrophil cytoplasmic antibody-associated vasculitis. Arthritis Rheumatol 71:1888-1893. https://doi.org/10.1002/art.41017
9. Kronbichler A, Leierer J, Leierer G et al (2017) Clinical associations with venous thromboembolism in anti-neutrophil cytoplasm antibody-associated vasculitides. Rheumatology (Oxford) 56:704-708. https://doi.org/10.1093/rheumatology/kew465

10. Kang A, Antonelou M, Wong NL et al (2019) High incidence of arterial and venous thrombosis in antineutrophil cytoplasmic antibody-associated vasculitis. J Rheumatol 46:285-293. https://doi.org/10.3899/jrheum.170896

11. Novikov P, Makarov E, Moiseev S, Meshkov A, Strizhakov L (2015) Venous thromboembolic events in systemic vasculitis. Ann Rheum Dis 74:e27. https://doi.org/10.1136/annrh eumdis-2014-206849

12. Al-Azzawi HF, Obi OC, Safi J, Song M (2016) Nephrotic syndrome-induced thromboembolism in adults. Int J Crit Illn Inj Sci 6:85-88. https://doi.org/10.4103/2229-5151.183019

13. Hilhorst M, Winckers K, Wilde B, Van Oerle R, Ten Cate H, Tervaert JWC (2013) Patients with antineutrophil cytoplasmic antibodies associated vasculitis in remission are hypercoagulable. J Rheumatol 40:2042-2046. https://doi.org/10.3899/ jrheum. 130200

14. Houben E, Penne EL, Voskuyl AE et al (2018) Cardiovascular events in anti-neutrophil cytoplasmic antibody-associated vasculitis: a meta-analysis of observational studies. Rheumatology (Oxford) 57:555-562. https://doi.org/10.1093/rheumatology/kex338

15. Hansrivijit $P$, Trongtorsak A, Gadhiya KP et al (2021) Incidence and risk factors of venous thromboembolism in ANCAassociated vasculitis: a metaanalysis and metaregression. Clin Rheumatol. https://doi.org/10.1007/s10067-021-05589-8

16. Ino Y, Baba A, Shinozaki M et al (2002) A case of ANCA-associated vasculitis with total thrombotic occlusion of the inferior vena cava. Respiration and Circulation 50:101-104

17. Pumerantz AW, Stout BJ, Tracy CL (2016) Granulomatosis with polyangiitis presenting as acute compartment syndrome. J Clin Rheumatol 22:225-228. https://doi.org/10.1097/RHU.00000 00000000407

18. Guo Y, Dai Y, Lai J, Fan Y (2013) Study about correlation of anti-neutrophil cytoplasmic antibodies and anticardiolipin antibodies with thromboangiitis obliterans. Vascular 21:363-368. https://doi.org/10.1177/1708538113478742

19. Kim MK, Kwon HC, Song JJ, Park YB, Lee SW (2021) Antineutrophil cytoplasmic antibody positivity is associated with vascular involvement in Behçet's disease. Yonsei Med J 62:149_ 158. https://doi.org/10.3349/ymj.2021.62.2.149

20. Gasparyan AY, Ayvazyan L, Blackmore H, Kitas GD (2011) Writing a narrative biomedical review: considerations for authors, peer reviewers, and editors. Rheumatol Int 31:14091417. https://doi.org/10.1007/s00296-011-1999-3

21. Nakazawa D, Masuda S, Tomaru U, Ishizu A (2019) Pathogenesis and therapeutic interventions for ANCA-associated vasculitis. Nat Rev Rheumatol 15:91-101. https://doi.org/10.1038/ s41584-018-0145-y

22. Kessenbrock K, Krumbholz M, Schönermarck U et al (2009) Netting neutrophils in autoimmune small-vessel vasculitis. Nat Med 15:623-625. https://doi.org/10.1038/nm.1959

23. Panda R, Krieger T, Hopf L et al (2017) Neutrophil extracellular traps contain selected antigens of anti-neutrophil cytoplasmic antibodies. Front Immunol 8:439. https://doi.org/10.3389/ fimmu.2017.00439

24. Nakazawa D, Shida H, Tomaru U et al (2014) Enhanced formation and disordered regulation of NETs in myeloperoxidase-ANCA-associated microscopic polyangiitis. J Am Soc Nephrol 25:990-997. https://doi.org/10.1681/asn.2013060606

25. Söderberg D, Kurz T, Motamedi A, Hellmark T, Eriksson P, Segelmark M (2015) Increased levels of neutrophil extracellular trap remnants in the circulation of patients with small vessel vasculitis, but an inverse correlation to anti-neutrophil 
cytoplasmic antibodies during remission. Rheumatology (Oxford) 54:2085-2094. https://doi.org/10.1093/rheumatolo $\mathrm{gy} / \mathrm{kev} 217$

26. Lood C, Hughes GC (2017) Neutrophil extracellular traps as a potential source of autoantigen in cocaine-associated autoimmunity. Rheumatology (Oxford) 56:638-643. https://doi.org/ 10.1093/rheumatology/kew256

27. Magro CM, Momtahen S, Harp J (2017) The distinctive histopathology of hydralazine-associated ANCA positive vasculitis: in vivo demonstration of NETosis. Eur J Dermatol 27:91-92. https://doi.org/10.1684/ejd.2016.2881

28. Nakazawa D, Tomaru U, Yamamoto C, Jodo S, Ishizu A (2012) Abundant neutrophil extracellular traps in thrombus of patient with microscopic polyangiitis. Front Immunol 3:333. https:// doi.org/10.3389/fimmu.2012.00333

29. Barnado A, Crofford LJ, Oates JC (2016) At the bedside: neutrophil extracellular traps (NETs) as targets for biomarkers and therapies in autoimmune diseases. J Leukoc Biol 99:265-278. https://doi.org/10.1189/jlb.5BT0615-234R

30. Butenas S, Orfeo T, Mann KG (2009) Tissue factor in coagulation: which? where? when? Arterioscler Thromb Vasc Biol 29:1989-1996. https://doi.org/10.1161/ATVBAHA.108.177402

31. Nightingale T, Cutler D (2013) The secretion of von Willebrand factor from endothelial cells; an increasingly complicated story. J Thromb Haemost: JTH 11(Suppl 1):192-201. https://doi.org/ $10.1111 /$ jth. 12225

32. Mast Alan E (2016) Tissue factor pathway inhibitor. Arterioscler Thromb Vasc Biol 36:9-14. https://doi.org/10.1161/ ATVBAHA.115.305996

33. Chavin SI (1984) Factor VIII: structure and function in blood clotting. Am J Hematol 16:297-306. https://doi.org/10.1002/ ajh. 2830160312

34. Kattula S, Byrnes JR, Wolberg AS (2017) Fibrinogen and Fibrin in Hemostasis and Thrombosis. Arterioscler Thromb Vasc Biol 37:e13-e21. https://doi.org/10.1161/ATVBAHA.117.308564

35. Chantarangkul V, Clerici M, Bressi C, Tripodi A (2004) Standardization of the endogenous thrombin potential measurement: how to minimize the effect of residual platelets in stored plasma. Br J Haematol 124:355-357. https://doi.org/10.1046/j.1365-2141.2003.04771.x

36. Brandt JT (2002) Plasminogen and tissue-type plasminogen activator deficiency as risk factors for thromboembolic disease. Arch Pathol Lab Med 126:1376-1381. https://doi.org/10.5858/ 2002-126-1376-PATTPA

37. Adam SS, Key NS, Greenberg CS (2009) D-dimer antigen: current concepts and future prospects. Blood 113:2878-2887. https://doi. org/10.1182/blood-2008-06-165845\%JBlood

38. Yu F, Zhao MH, Zhang YK, Zhang Y, Wang HY (2005) Antiendothelial cell antibodies (AECA) in patients with propylthiouracil (PTU)-induced ANCA positive vasculitis are associated with disease activity. Clin Exp Immunol 139:569-574. https://doi. org/10.1111/j.1365-2249.2005.02725.x

39. De Bandt M, Meyer O, Dacosta L, Elbim C, Pasquier C (1999) Anti-proteinase-3 (PR3) antibodies (C-ANCA) recognize various targets on the human umbilical vein endothelial cell (HUVEC) membrane. Clin Exp Immunol 115:362-368. https://doi.org/10. 1046/j.1365-2249.1999.00799.x

40. Antonelou M, Michaëlsson E, Evans RDR et al (2020) Therapeutic myeloperoxidase inhibition attenuates neutrophil activation, anca-mediated endothelial damage, and crescentic GN. J Am Soc Nephrol 31:350-364. https://doi.org/10.1681/ASN.2019060618

41. Salmela A, Ekstrand A, Joutsi-Korhonen L, Räisänen-Sokolowski A, Lassila R (2015) Activation of endothelium, coagulation and fibrinolysis is enhanced and associates with renal anti-neutrophil cytoplasmic antibody-associated vasculitis. Nephrol Dial Transplant 30:i53-i59. https://doi.org/10.1093/ndt/gfu379
42. Kambas K, Chrysanthopoulou A, Vassilopoulos D et al (2014) Tissue factor expression in neutrophil extracellular traps and neutrophil derived microparticles in antineutrophil cytoplasmic antibody associated vasculitis may promote thromboinflammation and the thrombophilic state associated with the disease. Ann Rheum Dis 73:1854-1863. https://doi.org/10.1136/annrh eumdis-2013-203430

43. Mendoza CE, Brant EJ, McDermott ML et al (2019) Elevated microparticle tissue factor activity differentiates patients with venous thromboembolism in anti-neutrophil cytoplasmic autoantibody vasculitis. Kidney Int Rep 4:1617-1629. https://doi.org/10. 1016/j.ekir.2019.07.006

44. Bautz DJ, Preston GA, Lionaki S et al (2008) Antibodies with dual reactivity to plasminogen and complementary PR3 in PR3-ANCA vasculitis. J Am Soc Nephrol 19:2421-2429. https://doi.org/10. 1681/ASN.2008030270

45. Merkel PA, Chang Y, Pierangeli SS, Convery K, Harris EN, Polisson RP (1996) The prevalence and clinical associations of anticardiolipin antibodies in a large inception cohort of patients with connective tissue diseases. Am J Med 101:576-583. https://doi. org/10.1016/s0002-9343(96)00335-x

46. Jordan N, D'Cruz DP (2016) Association of lupus anticoagulant with long-term damage accrual in antineutrophil cytoplasmic antibody-associated vasculitis. Arthritis Care Res (Hoboken) 68:711-715. https://doi.org/10.1002/acr.22723

47. Yoo J, Ahn SS, Jung SM, Song JJ, Park YB, Lee SW (2019) Persistent antiphospholipid antibodies are associated with thrombotic events in ANCA-associated vasculitis: a retrospective monocentric study. Nefrologia 39:395-401. https://doi.org/10.1016/j.nefro. 2018.10.014

48. Gulati S, Donato AA (2012) Lupus anticoagulant and ANCA associated thrombotic vasculopathy due to cocaine contaminated with levamisole: a case report and review of the literature. J Thromb Thrombolysis 34:7-10. https://doi.org/10.1007/ s11239-012-0711-0

49. Gaburri PD, Chebli JM, Attalla A et al (2005) Colonic ulcers in propylthiouracil induced vasculitis with secondary antiphospholipid syndrome. Postgrad Med J 81:338-340. https://doi.org/10. 1136/pgmj.2004.026104

50. Meng H, Yalavarthi S, Kanthi Y et al (2017) In vivo role of neutrophil extracellular traps in antiphospholipid antibody-mediated venous thrombosis. Arthritis Rheumatol 69:655-667. https://doi. org/10.1002/art.39938

51. Zuo Y, Yalavarthi S, Gockman K et al (2020) Anti-neutrophil extracellular trap antibodies and impaired neutrophil extracellular trap Degradation in antiphospholipid syndrome. Arthritis Rheumatol 72:2130-2135. https://doi.org/10.1002/art.41460

52. Chen H, Zhang W, Jing J et al (2019) The clinical and imaging features of hypertrophic pachymeningitis: a clinical analysis on 22 patients. Neurol Sci 40:269-274. https://doi.org/10.1007/ s10072-018-3619-4

53. Di Stefano V, Dono F, De Angelis MV, Onofrj M (2019) Hypertrophic pachymeningitis and cerebral venous thrombosis in myeloperoxidase-ANCA associated vasculitis. BMJ Case Rep 12:bcr2018-226780. https://doi.org/10.1136/bcr-2018-226780

54. Kuribayashi T, Manabe Y, Fujiwara S, Omote Y, Narai H, Abe $\mathrm{K}$ (2019) Combined hypertrophic pachymeningitis and cerebral venous thrombosis in a case of granulomatosis with polyangiitis. Case Rep Neurol 11:252-255. https://doi.org/10.1159/000502284

55. Misra D, Patro P, Sharma A (2019) Drug-induced vasculitis. Indian. J Rheumatol 14:3-9. https://doi.org/10.4103/0973-3698. 272156

56. Jenkins J, Babu K, Hsu-Hung E, Robinson-Bostom L, Kroumpouzos G (2011) ANCA-positive necrotizing vasculitis and thrombotic vasculopathy induced by levamisole-adulterated cocaine: a 
distinctive clinicopathologic presentation. J Am Acad Dermatol 65:e14-e16. https://doi.org/10.1016/j.jaad.2010.09.778

57. Pérez MRG, Ortiz-González VL, Betancourt M, Mercado R (2013) Cocaine-induced vasculitis: is this a new trend? Open Access Rheumatol 5:77-80. https://doi.org/10.2147/OARRR. S51524

58. Veronese FV, Dode RSO, Friderichs M et al (2016) Cocaine/ levamisole-induced systemic vasculitis with retiform purpura and pauci-immune glomerulonephritis. Braz J Med Biol Res 49:e5244. https://doi.org/10.1590/1414-431X20165244

59. Ohta K, Shimizu M, Yokoyama T et al (2007) Analysis of MPOANCA subtypes in a patient with propylthiouracil-induced vasculitis with multiple complications. Clin Nephrol 68:315-321. https://doi.org/10.5414/cnp68315

60. Antonucci A, Bardazzi F, Iozzo I, Patrizi A (2010) Necrotizing vasculitis in a patient affected by autoimmune hyperthyroidism treated with propylthiouracil. Dermatol Ther 23:S41-S43. https:// doi.org/10.1111/j.1529-8019.2010.01299.x

61. Wolf G, Porth J, Stahl RA (2001) Thrombosis associated with cytomegalovirus infection in patients with ANCA-positive vasculitis. Am J Kidney Dis 38:E27. https://doi.org/10.1053/ajkd. 2001.29576

62. Chirinos JA, Corrales-Medina VF, Garcia S, Lichtstein DM, Bisno AL, Chakko S (2007) Endocarditis associated with antineutrophil cytoplasmic antibodies: a case report and review of the literature. Clin Rheumatol 26:590-595. https://doi.org/10.1007/ s10067-005-0176-z

63. Misra DP, Chowdhury AC, Edavalath S, Aggarwal A, Kumar S, Agarwal V (2016) Endocarditis: the great mimic of rheumatic diseases. Trop Doct. https://doi.org/10.1177/0049475515624031[inpre ss]

64. Ahmed S, Zimba O, Gasparyan AY (2020) Thrombosis in coronavirus disease 2019 (COVID-19) through the prism of Virchow's triad. Clin Rheumatol 39:2529-2543. https://doi.org/10.1007/ s10067-020-05275-1

65. Leppkes M, Knopf J, Naschberger E et al (2020) Vascular occlusion by neutrophil extracellular traps in COVID-19. EBioMedicine 58:102925. https://doi.org/10.1016/j.ebiom.2020.102925
66. Nakazawa D, Ishizu A (2020) Immunothrombosis in severe COVID-19. EBioMedicine 59:102942. https://doi.org/10.1016/j. ebiom.2020.102942

67. Uppal NN, Kello N, Shah HH et al (2020) De novo ANCAassociated vasculitis with glomerulonephritis in COVID-19. Kidney Int Rep 5:2079-2083. https://doi.org/10.1016/j.ekir. 2020.08.012

68. Jalalzadeh M, Valencia-Manrique JC, Boma N, Chaudhari A, Chaudhari S (2021) Antineutrophil cytoplasmic antibody-associated glomerulonephritis in a case of scleroderma after recent diagnosis with COVID-19. Cureus 13:e12485. https://doi.org/10. $7759 /$ cureus. 12485

69. Martín Navarro JA, Cintra Cabrera M, Lucca Proccacini F et al (2021) More difficult still: treating severe rapidly progressive glomerulonephritis in the context of COVID-19 pneumonia. Nefrologia. https://doi.org/10.1016/j.nefro.2020.12.006

70. Powell WT, Campbell JA, Ross F, Peña Jiménez P, Rudzinski ER, Dickerson JA (2021) Acute ANCA vasculitis and asymptomatic COVID-19. Pediatrics. https://doi.org/10.1542/peds. 2020-033092

71. Selvaraj V, Moustafa A, Dapaah-Afriyie K, Birkenbach MP (2021) COVID-19-induced granulomatosis with polyangiitis. BMJ Case Rep 14:e242142. https://doi.org/10.1136/ bcr-2021-242142

72. Ahmed S, Zimba O, Gasparyan AY (2021) COVID-19 and the clinical course of rheumatic manifestations. Clin Rheumatol 1-9. https://doi.org/10.1007/s10067-021-05691-x

73. Gasparyan AY, Ayvazyan L, Mukanova U, Yessirkepov M, Kitas GD (2019) The platelet-to-lymphocyte ratio as an inflammatory marker in rheumatic diseases. Ann Lab Med 39:345-357. https:// doi.org/10.3343/alm.2019.39.4.345

74. Misra DP, Agarwal V (2016) Innate immune cells in the pathogenesis of primary systemic vasculitis. Rheumatol Int 36:169-182. https://doi.org/10.1007/s00296-015-3367-1

Publisher's note Springer Nature remains neutral with regard to jurisdictional claims in published maps and institutional affiliations. 